\title{
A RELAÇÃO EXISTENTE ENTRE O TRABALHO SOCIAL PROPOSTO POR ÉMILE DURKHEIM E O PRINCÍPIO CONSTITUCIONAL DA SOLIDARIEDADE PRESENTE NA CARTA MAGNA DE 1988
}

\author{
Jorge Renato dos Reis ${ }^{198}$ \\ Caroline Cristiane Werle ${ }^{199}$
}

Recebido em: 24/08/2016

Aprovado em: 15/09/2016

\section{RESUMO}

Este trabalho tem como objetivo principal verificar se existe, de fato, alguma relação entre o trabalho social proposto por Émile Durkheim e princípio constitucional da solidariedade, posto que ambos os elementos encontram proteção por parte da Constituição da República Federativa do Brasil de 1988. Dessa forma, num primeiro ensejo o artigo trará breves apontamentos acerca do trabalho social e, também, sobre o Direito do Trabalho. Na sequência, serão analisados os pressupostos históricos do princípio constitucional da solidariedade, bem como seu tratamento contemporâneo. Por fim, o trabalho irá verificar, com base nas principais características de cada instituto e, também, na obra "Da Divisão do Trabalho Social", de Émile Durkheim, se é possível estabelecer, de fato, alguma relação entre eles. Sem a pretensão de esgotar o assunto em pauta, acredita-se que as linhas gerais caracterizantes dos mecanismos aqui estudados são capazes de ensejar uma relação bastante próxima entre os mesmos, visto que, se ambos estão protegidos pela Carta Magna de 1988, é necessário que se harmonizem. Neste passo, considerando que o trabalho possui natureza bibliográfica, serão utilizados os métodos de abordagem dedutivo e histórico-crítico. Com relação à técnica de pesquisa, esta se valerá da documentação indireta.

Palavras-chave: Trabalho social. Princípio constitucional da solidariedade. Émile Durkheim. Divisão do trabalho social.

\footnotetext{
198 Pós-Doutor pela Università Degli Studi di Salerno, Itália. Doutor em Direito pela UNISINOS. Mestre em Desenvolvimento Regional pela UNISC. Especialista em Direito Privado. Professor e pesquisador do Programa de Pós-Graduação em Direito da Universidade de Santa Cruz do Sul - UNISC. Autor de diversos artigos em revistas jurídicas no Brasil, na Espanha e na Itália. Membro do Conselho Editorial de diversas revistas jurídicas no Brasil. Líder e pesquisador-membro do grupo de pesquisa "Intersecções Jurídicas entre o Público e o Privado", do Mestrado e Doutorado da UNISC. Endereço eletrônico: jreis@ viavale.com.br.

199 Mestranda do Programa de Pós-Graduação em Direito da Universidade de Santa Cruz do Sul (UNISC). Graduada em Direito pela Universidade de Santa Cruz do Sul - UNISC. Integrante do grupo de pesquisas "Intersecções Jurídicas entre o Público e Privado" coordenado pelo professor Pós-Doutor Jorge Renato dos Reis, Advogada. Endereço eletrônico: ccwerle@yahoo.com.br.
} 


\section{INTRODUÇÃO}

O trabalho evoluiu. Aliás, as premissas que permeiam o trabalho não somente evoluíram, como também contribuíram para aflorar o reconhecimento que essa importante atividade merece. Atualmente, o labor é considerado, mais do que algo necessário, uma forma de dignificar o homem. Contudo, a realidade nem sempre foi assim, porquanto o trabalho, nos primórdios, não era considerado algo a que se orgulhar.

A Constituição da República Federativa do Brasil de 1988 estabelece duas noções básicas que são essenciais no âmbito desta pesquisa: o princípio constitucional da solidariedade se trata de um objetivo da República; e o valor social do trabalho é um dos fundamentos do país. Desta feita, não há como negar que, a partir de um breve e rápido olhar, já é possível constatar a suposta existência de uma relação entre ambos os elementos mencionados.

Em face de tais reflexões, o presente artigo possui como objetivo principal analisar se é possível estabelecer uma relação entre o princípio constitucional da solidariedade e o trabalho social, levando-se em conta, para tanto, as principais linhas caracterizantes de cada elemento e, também, os ensinamentos tecidos por Émile Durkheim em sua obra "Da Divisão do Trabalho Social".

Destarte, o problema que se pretende responder neste artigo é o seguinte: é possível, analisando as principais características de cada instituto, estabelecer uma relação entre o princípio constitucional da solidariedade e o trabalho social proposto por Émile Durkheim? Assim, com o intuito de responder tal celeuma o trabalho foi dividido em três capítulos principais: num primeiro momento serão trazidos breves apontamentos acerca do trabalho social e, também, sobre o ramo do Direito que se destina a tutelá-lo. Superada tal parte, o artigo abordará o histórico do princípio constitucional da solidariedade, bem como seu tratamento na seara contemporânea. Por fim, será verificado se há, de fato, alguma relação entre os dois institutos aqui abordados, levando-se em conta, para tanto, as principais características de ambos e, sobremaneira, os ensinamentos contidos na obra "Da Divisão do Trabalho Social".

Nesse ínterim, considerando que a presente pesquisa possui natureza bibliográfica, os métodos de abordagem serão o dedutivo e o histórico-crítico. Relativamente à técnica de pesquisa, será aplicada a documentação indireta, baseando-se, para tanto, em obras doutrinárias, artigos científicos e periódicos relacionados à matéria em pauta. 


\section{BREVES APONTAMENTOS ACERCA DO TRABALHO SOCIAL}

O trabalho é a melhor e a pior das coisas: a melhor, se for livre; a pior, se for escravo. (Émile-Auguste Chartier)

Atualmente, não restam dúvidas quanto à importância do trabalho na vida humana, bem como no desenvolvimento da sociedade como um todo. $\mathrm{O}$ homem evoluiu e, junto com ele, as formas de trabalho também se modificaram. Desta feita, o presente artigo se propõe a verificar se há alguma relação entre o trabalho social estudado por Émile Durkheim e o princípio constitucional da solidariedade. Assim, para dar início à pesquisa, nada mais justo do que abordar, primeiramente, o que vem a ser o trabalho social - em suas linhas amplas -, perpassando, também, pelo ramo do Direito que se destina a regulá-lo.

Neste passo, já de antemão é importante que se faça uma breve distinção entre o direito ao trabalho e o Direito do Trabalho. O direito ao trabalho diz respeito ao acesso e à manutenção dos trabalhadores junto ao mercado de trabalho. Em contrapartida, o Direito do Trabalho "[...] consiste na proteção do trabalhador; na redução dos riscos inerentes ao trabalho, por meio de normas de saúde, higiene e segurança, conforme prevê o artigo $7^{\circ}$, inciso XXII, da Constituição Federal de 1988" (MACHADO; CARVALHO, 2014, p. 251). Esse apontamento inicial, ainda que bastante sucinto, permite tecer uma primeira ideia acerca do conteúdo que é velado pelo Direito do Trabalho. Contudo, não obstante a abordagem dos aspectos contemporâneos do ramo em voga seja importante, é imperioso que se traga à lume, também, a questão histórica e as transformações experimentadas pelo Direito do Trabalho ao longo do tempo.

No Brasil - país marcado por formação colonial, de economia essencialmente agrícola e com um sistema alicerçado na relação escravista de trabalho -, até o fim do século XIX não havia como estudar de forma precisa o Direito do Trabalho, visto que tal atividade não era algo livre para o homem ${ }^{200}$ (DELGADO, 2012, p. 105). Se hoje o trabalho é mais que uma necessidade - utilizado, também, como adjetivo para qualificar os indivíduos -, é de bom alvitre salientar que nem sempre foi assim.

\footnotetext{
${ }^{200}$ Nesse momento, se faz pertinente arrazoar uma ressalva proposta por Delgado (2012, p. 106): tal ideia não significa dizer que antes de 1888 não existia no Brasil qualquer experiência com relação de emprego; com industrialização; ou com traços tênues de regras jurídicas. Significa reconhecer que, nesse período específico, muito em razão da produção rural e da escravidão, não havia margem para o florescimento de condições que viabilizassem o ramo justrabalhista.
} 
Consoante aponta Delgado (2012, p. 106), em virtude do alastramento da escravidão por boa parte do solo brasileiro, não havia, naquela época, espaço sensível para o trabalho livre. O trabalho não tinha importância social; a industrialização era impraticável, posto que não poderia haver um processo diversificado; e não havia margem para a formação de grupos proletários e cidades proletárias capazes de gerar a união e a organização coletiva entre os homens. Como consequência, era inexistente todo e qualquer interesse do Estado em " [...] absorver os clamores vindos do plano térreo da sociedade" e criar marcos regulatórios para o trabalho humano (DELGADO, 2012, p. 106).

No entanto, o aludido cenário começa a experimentar algumas mudanças. Nesse âmago, sem margem para dúvida, é a partir da abolição da escravatura que há uma viragem de sentido no âmbito do trabalho no Brasil ${ }^{201}$. As atividades intelectuais deixaram de ser abominadas e passaram a ser encaradas como trabalhos imprescindíveis para o progresso da civilização. Consequentemente, em razão deste novo pano de fundo, as relações ocorridas entre empregado e empregador começaram a sofrer intervenção estatal, ou seja, o Estado passou a se preocupar em assegurar um catálogo de direitos que protegesse o elo mais fraco da relação ora mencionada: o empregado ${ }^{202}$ (REIS; NUNES, 2011, p. 54).

Nesse diapasão, o Direito do Trabalho, aqui abordado em sua acepção contemporânea, reflete a necessidade que o ordenamento jurídico possui de regulamentar a relação trabalhista, muito em razão da finalidade social contida nessa espécie de atividade. Destarte, o Direito do Trabalho se destina à proteção do trabalhador e de sua dignidade, especialmente porque o labor é considerado um exercício que dignifica a pessoa humana. Não obstante o referido ramo se destine a resguardar diversos bens jurídicos - a vida, a saúde, o meio ambiente, etc. -, a dignidade da pessoa humana sempre será o eixo principal de tutela do Direito (MACHADO; CARVALHO, 2014, p. 234-247). Desta feita, considerando que o trabalho dignifica o homem, isto é, promove a dignidade humana, não restam dúvidas de que ele está em plena consonância com o ordenamento jurídico brasileiro.

\footnotetext{
${ }^{201}$ No cenário mundial, a Revolução Industrial desempenhou um significativo papel no que diz respeito à história do Direito do Trabalho - iniciou na Inglaterra e posteriormente se espalhou para a Europa Continental, América do Norte e Japão. Se antes os trabalhadores detinham o processo produtivo em suas mãos, com a chegada da referida revolução tal controle foi perdido, uma vez que passaram a trabalhar para outrem. Desta feita, os empregados, muito em razão da busca incessante pelo capital por parte dos empregadores, passaram a sofrer com os seguintes efeitos: jornadas exaustivas, baixos salários, dentre outros. Todo esse contexto gerou reações por parte dos trabalhadores, os quais, unidos em sindicatos, acabaram reivindicando um direito que fosse capaz de protegêlos e, consequentemente, coibir os abusos advindos da relação de emprego (ARAÚJO; COIMBRA, 2013, p. 178). ${ }^{202}$ As relações de trabalho possuem como traço marcante a desigualdade existente entre as partes, sendo que o empregado e o empregador sempre estarão em uma relação de desequilíbrio. Essa situação ocorre porque trabalhador estará submisso às diretrizes, à fiscalização e à disciplina, que são fatores estipulados pelo empregador (SARMENTO; GOMES, 2011, p. 88).
} 
No entanto, consoante dispõe a Organização Internacional do Trabalho, não é qualquer trabalho que se coaduna com a dignidade da pessoa humana. Desta forma, para que seja capaz de dignificar o homem, o trabalho deve ser considerado decente. Mas o que é um trabalho decente? Segundo dispõem Reis e Nunes (2011, p. 63), o trabalho decente corresponde a um conjunto mínimo de direitos que devem ser garantidos aos empregados, os quais se traduzem nos seguintes dispositivos: existência de trabalho; liberdade de trabalho; igualdade de trabalho; trabalho em condições justas, isto é, que inclua remuneração e que preserve a saúde e a segurança do trabalhador; proibição do trabalho infantil; liberdade sindical; e proteção contra os riscos sociais.

Em outras palavras, não basta apenas que o trabalho exista. É imperioso que ele preencha os requisitos mínimos que possibilitem seu exercício em conformidade com a dignidade da pessoa humana e, mais do que isso, que ele seja capaz de promovê-la. Assim, o trabalho deve ser livre; deve ser desempenhado com igualdade; em condições justas; com remuneração adequada; em ambiente salubre; dentre outros fatores.

Neste passo, é cediço que, se em determinado momento histórico o trabalho sequer era visto como algo digno, nos dias atuais a realidade se revela completamente diferente nesse aspecto. Hodiernamente, o exercício do trabalho, além de ser protegido, é amplamente promovido, sendo que essa proteção/promoção se dá em razão de duas principais vertentes: o trabalho decente dignifica o homem e impulsiona o desenvolvimento da sociedade e de todos os elementos que dela fazem parte. Por esse motivo, bem como em virtude do avanço das tecnologias e do crescimento do mercado de consumo, é imperioso que haja uma proteção efetiva ao trabalho, sendo que, dessa forma, será possível revelar o seu valor social.

A Constituição da República Federativa do Brasil de 1988 afirmou, em seu artigo 6º que o direito ao trabalho se trata de um direito social fundamental, sendo que tais direitos têm por finalidade permitir que as pessoas disponham de serviços que garantam uma mínima qualidade de vida ${ }^{203}$. Em outras palavras, os direitos sociais fundamentais "podem ser identificados como um conjunto de normas jurídicas de origem estatal destinadas a proteger os fracos e hipossuficientes [...]" (MACHADO, 2012, p. 239). Além da previsão contida no artigo $6^{\circ}$, a Magna Carta de 1988 trouxe, também, o valor social do trabalho como um dos

\footnotetext{
${ }^{203}$ Artigo 60: "São direitos sociais a educação, a saúde, a alimentação, o trabalho, a moradia, o transporte, o lazer, a segurança, a previdência social, a proteção à maternidade e à infância, a assistência aos desamparados, na forma desta Constituição" (BRASIL, 1988, www.planalto.gov.br).
} 
fundamentos da República Federativa do Brasil em seu artigo $1^{\circ}$, inciso IV, evidenciando, assim, a importância desse elemento para a sociedade nacional ${ }^{204}$.

Não satisfeita com a previsão desses dois dispositivos, a Constituição da República Federativa do Brasil de 1988 foi mais além. No caput do artigo 170 a referida Carta aponta que a valorização do trabalho humano faz parte da ordem econômica do país ${ }^{205}$. Nessa mesma linha de raciocínio, enaltecendo ainda mais a aludida atividade, o artigo 193 do mesmo diploma aduz que a ordem social tem como base principal o trabalho ${ }^{206}$.

No entanto, de nada adiantaria o texto constitucional estabelecer a importância do trabalho em inúmeras passagens, se o mesmo não trouxesse a possibilidade de proteção prática desse direito. Em virtude disso, o artigo $7^{\circ}$ traz uma gama de direitos concernentes aos trabalhadores urbanos e rurais: garantia de salário nunca inferior ao mínimo estabelecido; gozo de férias anuais remuneradas; redução dos riscos; dentre diversos outros. Ademais, muito embora o referido artigo contenha um número determinado de incisos, a Constituição reconhece expressamente todos os demais direitos que tiverem como escopo a melhoria da condição social dos referidos trabalhadores.

Em face de tais aportes, cabe trazer à colação a sintetização desenvolvida por Reis e Antonelo (2011, p. 53), a qual dispõe acerca da proteção constitucional concedida ao labor:

O texto constitucional pátrio garante proteção ao trabalho, estabelecendo sua importância em distintos momentos: no seu artigo $1^{\circ}$ preceitua que os valores sociais do trabalho representam um dos fundamentos do Estado Democrático de Direito; o artigo $6^{\circ}$ estabelece que o trabalho é um dos direitos sociais e o artigo $7^{\circ}$ trata da proteção a esse direito; o artigo 170 preceitua que o trabalho humano é um dos valores da ordem econômica; e o artigo 193 o define como base da ordem social ${ }^{207}$.

Frente ao conteúdo dos dispositivos mencionados, é possível perceber que o desenvolvimento da ordem econômica está intimamente vinculado a dois fatores primordiais: a forma com que o Estado trata o trabalho exercido por seus cidadãos; e o reflexo provocado

\footnotetext{
${ }^{204}$ Artigo 1 1: "A República Federativa do Brasil, formada pela união indissolúvel dos Estados e Municípios e do Distrito Federal, constitui-se em Estado Democrático de Direito e tem como fundamentos: [...] IV - os valores sociais do trabalho e da livre iniciativa [...]" (BRASIL, 1988, www.planalto.gov.br).

${ }^{205}$ Art. 170: "A ordem econômica, fundada na valorização do trabalho humano e na livre iniciativa, tem por fim assegurar a todos existência digna, conforme os ditames da justiça social [...]" (BRASIL, 1988, www.planalto.gov.br).

${ }^{206}$ Art. 193: "A ordem social tem como base o primado do trabalho, e como objetivo o bem-estar e a justiça sociais" (BRASIL, 1988, www.planalto.gov.br).

${ }^{207}$ No âmbito da Declaração Universal dos Direitos Humanos, diferentemente da dignidade da pessoa humana, o valor social do trabalho não surge de forma expressa. Contudo, quando da leitura da referida Carta, percebe-se que o princípio do valor social do trabalho está presente, ainda que implicitamente, no artigo 23 , uma vez que o mesmo fixa a mínima proteção do livre trabalho; estabelece a igualdade de condições entre trabalhadores; reconhece a capacidade de organização sindical; e, sobretudo, por decorrência da dignidade humana, afirma que o trabalho deve ser respeitado (ONU, 1948, www.dudh.org.br).
} 
pelo labor no âmbito do sistema. Assim, o amparo se dá em uma via de mão dupla, porquanto ao conceder proteção ao trabalho, visto que este acarreta reflexos sociais, o Estado está influenciando positivamente o desenvolvimento de sua própria economia (GÓES; ENGELMANN, 2015, p. 49).

Não restam dúvidas de que a Constituição da República Federativa do Brasil de 1988 lançou seu manto protetor sob o Direito do Trabalho. Tal fato, além de enaltecer a importância desse direito para o ordenamento pátrio e para a sociedade como um todo, amplia o próprio valor - em todos os setores - concedido ao labor. Contudo, a sua tutela contemporânea vai ainda mais além, perpassando pela própria interpretação do Direito na atualidade.

Se no liberalismo clássico os direitos fundamentais se estendiam apenas às relações nas quais o Estado figurava como parte, atualmente não é bem assim. Na esfera atual, considerando que a "violência" contra a pessoa é praticada não somente pelo Estado, mas também por particulares, não há como negar que os direitos fundamentais devem incidir, inclusive, no âmbito das relações privadas. Nesse âmago, Sarmento e Gomes (2011, p. 60) fazem uma pertinente afirmação: no cenário brasileiro, “excluir as relações privadas do raio de incidência dos direitos fundamentais importa em mutilar seriamente estes direitos, reduzindo a sua capacidade de proteger e promover a dignidade da pessoa humana" ${ }^{208}$.

Portanto, não restam dúvidas de que os preceitos presentes na Constituição da República Federativa do Brasil de 1988 devem irradiar sua força por todo o ordenamento jurídico infraconstitucional, ou seja, devem ser observados em todas as relações - sejam elas públicas ou privadas -, funcionando, no mínimo, como um vetor de interpretação (SARLET, 2012, p. 48-49).

Partindo para a conclusão deste capítulo, restou bastante claro que o valor social do trabalho possui duas facetas, quais sejam: a primeira diz respeito a sua tarefa de exigir que o trabalho seja sempre considerado a partir de um conceito de dignidade; e a segunda refere-se ao papel do labor junto à sociedade e a necessidade de sua proteção por parte do Estado, porquanto seu caráter digno deve ser sempre conservado. Nesse contexto, "não se pode considerar o trabalho como mera atividade, mas sim, como um efetivo dispêndio de mão de

\footnotetext{
${ }^{208}$ É de bom alvitre destacar que, com a incidência dos direitos fundamentais no âmbito das relações entre particulares, não se quer dizer que a autonomia privada restará aniquilada do ordenamento jurídico. A referida assertiva significa que, em determinados casos concretos, ela será ponderada. Ademais, excetuadas as situações específicas, o empregador privado não se equipara ao Estado. Dessa forma, considerando que o mesmo detém maior liberdade, ele pode, por exemplo, fazer sua própria escolha com relação à contratação de empregados respeitando, obviamente, a redação legal (SARMENTO; GOMES, 2011, p. 88).
} 
obra a favor de outrem, configurando-se como 'socialmente útil'” (GÓES; ENGELMANN, 2015, p. 53).

Desta forma, não restam dúvidas de que o valor social do trabalho se afigura como um princípio constitucional, devendo ser observado por todos - seja numa relação pública, como numa relação privada -. Dito isto, parte-se para o próximo capítulo deste artigo, o qual analisará o princípio constitucional da solidariedade, pois somente perpassando por sua abordagem é que será possível verificar se há, de fato, uma relação entre o valor social proposto por Émile Durkheim e a perspectiva solidarista.

\section{O PRINCÍPIO CONSTITUCIONAL DA SOLIDARIEDADE: DAS ORIGENS À CONTEMPORANEIDADE}

Nunca mandes perguntar por quem os sinos dobram: eles dobram por ti. (John Donne)

Muito embora o ideal de solidariedade tenha sido institucionalizado recentemente no seio da sociedade, ele se trata de um elemento extremamente antigo, ainda que nos primórdios estivesse, na maioria dos casos, vinculado aos conceitos de caridade e fraternidade - que não se confundem com solidariedade. Sob este enfoque, é de bom alvitre adiantar que o estudo do ideal solidarista comporta duas principais vertentes, quais sejam: a solidariedade com cunho filosófico, que nasce a partir do ideal de ajuda ao próximo; e a solidariedade com viés sociológico, que surge da necessidade de haver uma boa convivência entre os homens dentro de uma sociedade (SOARES, 2009).

A solidariedade com cunho filosófico teve seu início mediante a obra "A República", que foi escrita pelo filósofo grego Platão no século IV a.C. Das diversas passagens do texto, em uma delas, mais precisamente em um diálogo ocorrido entre Sócrates e Glauco, há claramente a presença de ideários relativos à unidade social, os quais evidenciam uma forte crítica ao individualismo.

Nas obras de Aristóteles, por sua vez, o ideal solidarista é percebido quando o mesmo discorre acerca da justiça e da virtude. O referido filósofo aduz que, para o homem ser virtuoso, é preciso que ele encontre a felicidade e a boa sorte, sendo que a justiça é uma virtude completa, de modo que o indivíduo que a possui deve exercer sua virtude não só com relação a si próprio, mas, também, com relação ao próximo. Destarte, o indivíduo é uma pessoa virtuosa não somente quando cumpre a lei a seu favor, mas quando o faz em prol da comunidade, isso 
porque, na visão aristotélica, a virtude possui estreita relação com o "fazer bem ao próximo" (ARISTÓTELES, 2012, p. 96).

Nessa mesma linha de pensamento, Aristóteles deixa ainda mais evidente a presença do ideário solidarista quando afirma que "o homem, por natureza, é um animal político, isto é, destinado a viver em sociedade" (ARISTÓTELES, 2008, p. 56). Para ele, o homem que não consegue viver em coletividade ou que não necessita de outros indivíduos para viver, não faz parte da pólis, visto que possui a pretensão de bastar-se em si mesmo (ARISTÓTELES, 2008, p. 57). Assim sendo, a pessoa, no sentido filosófico pregado por Aristóteles, está fundada em um ser que necessita dos outros para se estabelecer, devendo observar seu semelhante e voltar suas atitudes para a coletividade ${ }^{209}$.

Não restam dúvidas de que a Antiguidade Clássica possui importante papel no que diz respeito à origem da solidariedade, muito embora alguns autores afirmem que nesta época não tenha sido estabelecido um ideal realmente solidarista. No entanto, há outro elemento igualmente essencial no âmbito da história da solidariedade, qual seja: o cristianismo. Não obstante seja possível notar um distanciamento cada vez maior entre os indivíduos e as religiões, certamente provocado pelo ritmo de vida acelerado e individualista dos tempos contemporâneos, o cristianismo serviu de alicerce para a teoria da justiça clássica, que teve como principais expoentes Santo Agostinho e São Tomás de Aquino (BODENHEIMER, 1994, p. 85).

Ambos os teólogos, carregando inspiração cristã, reafirmaram que a caridade seria a mais pura expressão da justiça divina. Nesse sentido, Santo Agostinho, além de arguir que as pessoas não deveriam conceder excessivo valor aos bens materiais e que não havia como chegar à felicidade desprezando o próximo, apontou que a justiça propriamente dita estava pautada em Deus, uma vez que a justiça aplicada pelos homens não era considerada completa (AGOSTINHO, 2000, p. 1.929). Nesse mesmo contexto, São Tomás de Aquino afirmou que o indivíduo possui uma inclinação natural para viver em sociedade e, inclusive, para conceber como verdade a figura de Deus. Tal inclinação faz com que os homens se afastem da ignorância e das ofensas ao próximo (BODENHEIMER, 1994, p. 150).

Com o passar do tempo, já na Idade Média - a partir do século IV d.C. -, os pensamentos filosóficos relativos aos laços que aproximavam os homens foram perdendo força. A referida situação perdurou por cerca de dez séculos, sendo que o regime feudal, influenciado pela

\footnotetext{
${ }^{209}$ Contudo, é preciso tomar cuidado com o seguinte: muito embora os indivíduos devam voltar suas atitudes para a coletividade, é necessário que eles disponham de uma esfera de direitos que possibilite o desenvolvimento de sua própria personalidade e de seus talentos.
} 
dogmática religiosa e pela ideia de que o servo deveria servir ao seu senhor, não favoreceu o desenvolvimento de teorias acerca da solidariedade (OLIVEIRA, 2014, p. 16).

Entretanto, em virtude do fim do feudalismo o cenário supramencionado começou se alterar, especialmente devido ao surgimento do Renascentismo e, posteriormente, do Iluminismo. Ambos os períodos históricos ora destacados foram marcados pelo nascimento do método científico e das grandes teorias que guiaram - e guiam até os dias atuais - a ciência, os quais influenciaram a busca por fundamentações racionais para o sentido da vida e do indivíduo (BODENHEIMER, 1994).

Em face dessa evolução, surge a teoria contratualista, a qual preceitua que o Estado é fruto da ficção humana e que o mesmo tem como objetivo primordial possibilitar a convivência coletiva. Dessa forma, a referida teoria, ao estabelecer a pessoa como condição para o surgimento do Estado, acaba por elevar o significado do próprio homem. Nesta mesma esteira, o direito passa a estar desvinculado da natureza sagrada, fundando-se na razão humana (BODENHEIMER, 1994).

Neste ramo, as teorias desenvolvidas por Hugo Grócio, por Samuel Puffendorf, e pelos contratualistas Thomas Hobbes, John Locke e Jean-Jacques Rousseau deram ensejo para o surgimento da chamada Escola Clássica do Direito Natural e, ao servirem de base para o Código Napoleônico ${ }^{210}$, semearam a ideia de que o indivíduo é um ser possuidor de direitos, os quais são garantidos devido a sua simples qualidade de ser humano e, também, de que existem normas que são superiores e obrigatórias aos governantes (BODENHEIMER, 1994, p. 75).

Sem dúvida, as teorias construídas pelos pensadores ora mencionados foram fundamentais para compreender a formação do Estado e suas premissas, sobremaneira no que diz respeito à compreensão de como o indivíduo era visto por tais pensadores: num primeiro momento como ser egoísta, sem qualquer sentimento fraterno; e, num segundo momento, como uma pessoa relativamente boa, que se une aos demais e cria o Estado com o intuito de manter o sentimento de paz social (OLIVEIRA, 2014, p. 18).

No entanto, devido às características típicas do modelo estatal instaurado nesta época Estado Liberal -, o mesmo não foi sensível à ideia de solidariedade (CARDOSO, 2013, p. 132). Sob o pretexto de valorização do indivíduo, afora os benefícios trazidos, o liberalismo deu largo ensejo à degradação do homem, especialmente porque tal modelo assegurou uma relação de privilégio às pessoas economicamente mais fortes. Dessa forma, considerando que os valores

\footnotetext{
${ }^{210}$ O Código Napoleônico - também conhecido como Code de France -, cujo modelo serviu de inspiração para os códigos promulgados posteriormente, foi um código marcado pelo conservadorismo e ficou conhecido como o marco histórico das liberdades individuais.
} 
econômicos foram colocados em um patamar superior a todos os demais, quem passou a ter o domínio da sociedade foram os homens desprovidos de qualquer formação humanística, cujo único intuito pessoal era aumentar o capital e a riqueza (DALLARI, 2000, p. 277-278).

Nesse mesmo âmago, a Revolução Industrial, além de impulsionar, deixou evidente a exploração do homem sobre o homem ${ }^{211}$. Assim, muito em razão da crescente degradação das relações humanas, surgiram as teorias socialistas, as quais tinham como principal escopo trazer melhorias à classe operária e, consequentemente, à vida das pessoas como um todo. Evidentemente, a ideia de cooperação na busca por melhorias no campo individual, que se traduziu na criação de sindicatos e associações, foi uma forma bastante eficaz que os indivíduos encontraram para dar início à luta contra a miserabilidade e, igualmente, para recuperar a boa relação entre os homens (CARDOSO, 2013, p. 145).

A partir desses aportes, é possível falar acerca da solidariedade com cunho sociológico, porquanto essa busca por direitos sociais, os quais permitiriam uma melhor qualidade de vida aos operários e à toda população, ensejou o surgimento da sociologia. Fundada no estudo da sociedade como um todo, sem pormenorizar os indivíduos, a referida ciência defende a ideia de que o conjunto de pessoas forma algo maior do que simplesmente a união de indivíduos (LEVINE, 1997). Assim, para a sociologia a solidariedade se afigura como um elemento de qualificação na relação entre indivíduos, visto que traz consigo a noção de cooperação, ou seja, para que os indivíduos tenham uma vida minimamente digna, todos são responsáveis pelo suprimento das necessidades individuais e, inclusive, das necessidades do próprio grupo social $^{212}$.

De fato, as contribuições advindas das vertentes ora analisadas foram fundamentais para a construção da ideia de solidariedade na atualidade. No entanto, o elemento aqui estudado vai muito além das questões filosóficas, cristãs e sociológicas. É a partir do final do século XIX que a solidariedade ultrapassa os discursos filantrópicos, fraternos e de caridade, e passa a ser vista, muito em razão da solidariedade social, de outra maneira: como solidariedade jurídica (WESTPHAL, 2008, p. 44-45).

Neste contexto, surgem algumas dúvidas: o que é, de fato, a solidariedade para os dias atuais e, também, o que vem a ser a solidariedade jurídica? Segundo explica Moraes (2008, p. 243), a solidariedade, contemporaneamente falando, pode ser analisada sob diversos enfoques:

\footnotetext{
${ }^{211}$ É cediço que a Revolução Industrial acarretou uma grave degradação do homem. Contudo, não há como negar que a referida revolução trouxe efeitos positivos, de modo que nesse período houve o reconhecimento de inúmeros direitos sociais aos cidadãos.

${ }^{212}$ Insta referir que os ensinamentos tecidos por Émile Durkheim acerca da solidariedade serão abordados de forma mais aprofundada no último capítulo desta pesquisa.
} 
como um fato social inerente ao homem, visto que a solidariedade é parte de sua condição como ser no mundo; como uma virtude ética ainda mais ampla do que a justa conduta - ceder o que é seu ao próximo -; como resultado da consciência moral e da boa-fé; etc.

Por outro lado, de acordo com o viés jurídico

a solidariedade está contida no princípio geral instituído pela Constituição de 1988 para que, através dele, se alcance o objetivo da 'igual dignidade social'. O princípio da solidariedade identifica-se, desse modo, com o conjunto de instrumentos voltados para garantir uma existência digna, comum a todos, em uma sociedade que se desenvolva como livre e justa, sem excluídos ou marginalizados (MORAES, 2008, p. 243).

Indubitavelmente, o aspecto jurídico da solidariedade visa superar a primazia do individualismo típico do Estado Liberal, ou seja, um de seus principais objetivos consiste em reunir as pessoas sob a perspectiva do bem comum e, além disso, trazer a ideia de responsabilidade para com o próximo (REIS; KONRAD, 2015, p. 79). O mais importante nessa viragem de rumo da solidariedade é compreender que ela não se trata de um dever positivo apenas por parte do Estado, mas, também, que enseja deveres recíprocos entre as pessoas, visto que os indivíduos não conseguem viver se não em sociedade ${ }^{213}$ (LÔBO, 2009, p. 325).

Desta feita, a Constituição da República Federativa do Brasil de 1988 foi bastante sensível à ideia solidarista e a trouxe expressamente em seu artigo $3^{\circ}$, inciso I: “[...] constituem objetivos fundamentais da República Federativa do Brasil: I - construir uma sociedade livre, justa e solidária [...]” (BRASIL, 1988). Assim, no âmbito jurídico brasileiro a solidariedade possui um duplo sentido, qual seja: por um lado se enquadra como um dos objetivos fundamentais do Estado e, por outro, constitui um dos princípios fundamentais do ordenamento jurídico ${ }^{214}$.

Sem margem para dúvida, um dos objetivos primordiais do princípio constitucional da solidariedade consiste em promover a dignidade da pessoa humana. Para isso, o mesmo cria instrumentos que sejam capazes de impulsionar o crescimento da sociedade de uma forma igualitária e justa. Este intuito parece encontrar certa harmonia com o trabalho social e, também, com o seu valor perante os homens. Se os preceitos constitucionais devem ser lidos conjuntamente, é amplamente possível que exista uma relação entre a perspectiva solidarista e

\footnotetext{
${ }^{213}$ Sem margem para dúvida, a Declaração Universal dos Direitos Humanos, promulgada em 10 de dezembro de 1948, é o instrumento jurídico que afirmou e assentou a força normativa da solidariedade na era contemporânea. ${ }^{214}$ Insta mencionar que a presença expressa da solidariedade na Constituição da República Federativa do Brasil de 1988 é fruto de dois importantes acontecimentos: o primeiro, de ordem interna, deve-se ao fato de o país ter passado por um longo período ditatorial, no qual diversos direitos básicos dos indivíduos foram suprimidos; e o segundo, de ordem global, que diz respeito à evolução dos direitos fundamentais, os quais, após a Segunda Guerra Mundial, voltaram seu norte para o princípio da dignidade da pessoa humana.
} 
o valor social do trabalho, mesmo porque ambos estão expressamente presentes na Carta Magna de 1988.

Frente a tais apontamentos, no próximo e derradeiro capítulo será verificado se existe, de fato, alguma relação entre o princípio constitucional da solidariedade e o trabalho social estudado pelo sociólogo Émile Durkheim, levando-se em conta, para tanto, as principais linhas caracterizantes de cada instituto.

\section{A RELAÇÃO ENTRE O TRABALHO SOCIAL PROPOSTO POR ÉMILE DURKHEIM E O IDEÁRIO SOLIDARISTA PRESENTE NA CONSTITUIÇÃO DA REPÚBLICA FEDERATIVA DO BRASIL DE 1988}
A maior recompensa pelo nosso trabalho não é o que nos pagam por ele, mas aquilo em que ele nos transforma. (John Ruskin)

Como forma de conceder subsídios suficientes para a pesquisa, nos capítulos anteriores foram analisados, em aspectos gerais, o trabalho social, bem como o princípio da solidariedade, perpassando por sua história e seu tratamento constitucional atual. Para tanto, neste capítulo o presente artigo adentrará especificamente na divisão do trabalho social proposta por Émile Durkheim e, posteriormente, verificará se existe, de fato, uma relação entre o referido elemento e a perspectiva solidarista.

Considerando que a obra “Da Divisão do Trabalho Social”, escrita por Émile Durkheim, foi eleita como matriz teórica para o desenvolvimento do presente capítulo, nada mais justo do que esclarecer os principais aspectos por ela tratados. Destarte, o livro ora mencionado analisa a função existente na divisão do trabalho social e, ainda, verifica em que medida a referida divisão pode contribuir para a sociedade.

Assim sendo, já de antemão Durkheim (1999, p. 30) faz uma importante ressalva, a qual influencia o rumo que este capítulo tomará: os homens não devem procurar se a solidariedade social proveniente da divisão do trabalho está presente na sociedade, porquanto esse fato é notório/evidente. Para o autor em voga, é imprescindível "[...] determinar, sobretudo, em que medida a solidariedade que ela produz contribui para a integração geral da sociedade, pois somente então saberemos até que ponto essa solidariedade é necessária” (DURKHEIM, 1999, p. 30). 
Em face da tal afirmação, o sociólogo francês, alicerçando-se no pensamento de Auguste Comte, propõe o seguinte questionamento: a divisão do trabalho humano seria, de fato, o elemento responsável pela constituição da solidariedade social? Desta feita, Émile Durkheim aduz que, se a resposta para essa pergunta for positiva, não restam dúvidas de que a

[...] divisão do trabalho desempenharia um papel muito mais importante do que aquele que se the atribui ordinariamente. Ela não serviria apenas para dotar nossas sociedades de um luxo, invejável talvez, mas supérfluo; ela seria uma condição de sua existência. É, por ela, ou pelo menos é sobretudo por ela, que estaria assegurada sua coesão; é ela que determinaria os traços essenciais de sua constituição (DURKHEIM, 1999, p. 29$30)$.

A passagem ora transcrita evidencia o quanto a divisão do trabalho social pode ser essencial para a perspectiva solidarista, porquanto o referido autor busca verificar se esta deriva fundamentalmente daquela. Ainda que a resolução desta questão perpasse por caminhos sinuosos, resta bastante claro que, se a função da divisão do trabalho social é trazer coesão à sociedade, "ela deve ter um caráter moral, porque as necessidades de ordem, de harmonia, de solidariedade social são geralmente tidas como morais" (DURKHEIM, 1999, p. 30).

Objetivando esclarecer em que medida a solidariedade advinda da divisão do trabalho é um fator essencial à coesão social, Durkheim passa a classificar as espécies de solidariedade social existentes. Nesse ínterim, revela-se bastante interessante a reflexão que o aludido autor faz quanto à relação existente entre a solidariedade social e o Direito: a vida social, onde quer que ela exista de maneira duradoura, tende a tomar uma forma definida e a se organizar. O Direito, por sua vez, nada mais é do que essa organização em sua configuração mais estável e precisa. Diante disso, "a vida geral da sociedade não pode se estender num ponto sem que a vida jurídica nele se estenda ao mesmo tempo e na mesma proporção" (DURKHEIM, 1999, p. 31-32). Portanto, é possível afirmar que todas as variantes da solidariedade social poderão estar refletidas no Direito.

Contudo, cabe efetuar uma pequena advertência: isso não significa dizer, necessariamente, que todos os tipos de solidariedade social são positivados pelo Direito. É imperioso enfatizar que alguns tipos secundários de solidariedade social podem derivar apenas do costume. Entretanto, o que importa, de fato, são os tipos de solidariedade social reproduzidas pelo Direito, visto que essas se afiguram como formas essenciais de solidariedade (DURKHEIM, 1999, p. 31-32).

Consoante o escólio de Émile Durkheim, a solidariedade, por se tratar de um fato social, é um elemento pertencente à ciência da sociologia. Além disso, os homens somente conseguem conhecê-la a partir dos efeitos sociais que ela causa. Inevitavelmente, a solidariedade varia de 
acordo com o grupo social que ela se propõe a dar coesão e, assim sendo, existem diferenças entre a solidariedade manifestada no âmbito familiar e a solidariedade externada na seara profissional, por exemplo (DURKHEIM, 1999, p. 33).

Nesse diapasão, oportuno salientar os apontamentos construídos por Musse (2007, p. 13):

Cada indivíduo bebe, dorme, come, pensa, raciocina, e a sociedade tem todo interesse em que essas funções sejam regularmente exercidas. Porém, se esses fatos fossem sociais, a sociologia não teria objeto próprio, e seu domínio se confundiria com o da biologia e o da psicologia.

Diante de tal raciocínio, é possível perceber que a solidariedade, quando encarada como um fenômeno apenas psíquico ou biológico, é algo indefinível e intangível. Deste modo, para que possa ser observada é necessário que produza alguma consequência social (DURKHEIM, 1999, p. 33).

Levando-se em consideração que o direito é um reprodutor das espécies de solidariedade social, é necessário, primeiro, classificar as espécies de Direito para, posteriormente, conectálas às formas de solidariedade. Destarte, o referido autor elege o seguinte "método": as normas jurídicas devem ser classificadas de acordo com suas sanções, ou seja, de um lado estão aquelas responsáveis pela imposição de "dor" ao agente - repressivas - e, de outro, estão aquelas que reestabelecem o estado daquilo que foi perturbado - restitutivas. A partir desses aportes, é possível adentrar na solidariedade mecânica - também chamada de solidariedade por similitude - e na solidariedade orgânica (DURKHEIM, 1999, 34).

Consoante assevera Cardoso (2013, p. 137), em uma sociedade de solidariedade mecânica, os indivíduos estão diretamente vinculados à sociedade, isto é, os sujeitos, enquanto seres sociais, direcionam o seu comportamento para onde aponta a consciência coletiva, deixando de lado seus interesses enquanto indivíduos. Nesse tipo de solidariedade, a maior parte da existência das pessoas é orientada pelos imperativos e proibições sociais provenientes da consciência coletiva. Com efeito, "quanto mais forte a consciência coletiva, maior a intensidade da solidariedade mecânica"215 (CARDOSO, 2013, p. 137).

Contudo, considerando que a sociedade evolui socialmente, ela acaba transformando a solidariedade mecânica em uma solidariedade orgânica, isto é, a solidariedade mecânica menos complexa e formada pelo predomínio do grupo sobre o indivíduo - cede espaço para a

\footnotetext{
215 Importante frisar que a duração da consciência coletiva é sempre maior do que a vida individual, posto que os indivíduos se vão, mas a consciência coletiva permanece na mente das gerações. Ademais, é em virtude das mentalidades coletivas que são moldadas a cultura, os costumes, e as formas de organização política e da atividade econômica (COMPARATO, 2013).
} 
solidariedade orgânica, a qual é mais complexa e possui intrínseca vinculação com a divisão do trabalho social (CAETANO, [s.a.], p. 2-3).

De acordo com os ensinamentos tecidos por Cardoso (2013, p. 137), na solidariedade orgânica, além de ocorrer um enfraquecimento das reações coletivas em face da violação das proibições, há, sobretudo, uma ampliação na margem de interpretação individual dos imperativos sociais. Portanto,

na solidariedade orgânica ocorre um processo de individualização dos membros dessa sociedade, os quais assumem funções específicas dentro dessa divisão do trabalho social. Cada pessoa é uma peça de uma grande engrenagem, na qual cada um tem sua função e é esta última que marca seu lugar na sociedade. A consciência coletiva tem seu poder de influência reduzido, criando-se condições de sociabilidade bem diferentes daquelas vistas na solidariedade mecânica, havendo espaço para o desenvolvimento de personalidades. Os indivíduos se unem não porque se sentem semelhantes ou porque haja consenso, mas sim porque são interdependentes dentro da esfera social (CARDOSO, 2013, p. 138).

O que se percebe na solidariedade orgânica é algo um pouco diferente do que se verifica na solidariedade mecânica. Na solidariedade de tipo orgânica não há um sufocamento das aptidões de cada indivíduo, mas, sim, a promoção de seu crescimento mediante a conexão dessas aptidões com as qualidades de outras pessoas. Tal entendimento leva a crer que é o compartilhamento e a cooperação que irão direcionar os indivíduos - e a própria sociedade para o caminho do desenvolvimento.

Nesta mesma esteira, cabe trazer à lume alguns ensinamentos propostos por Léon Duguit, o qual, fazendo expressa referência à Émile Durkheim, abordou a solidariedade social e enfatizou que os laços de solidariedade são capazes de vincular as pessoas pertencentes a um mesmo grupo. Tais laços podem ser criados em virtude de necessidades em comum solidariedade mecânica - ou, ainda, devido ao fato de que os sujeitos, por possuírem anseios e aptidões diversas, dependem uns dos outros para efetuarem a troca desses fatores solidariedade orgânica (DUGUIT, 2006, p. 25).

Frente a tais aportes, não restam dúvidas de que a ideia do trabalho social desenvolvida por Émile Durkheim possui inúmeras aproximações para com as principais características definidoras do princípio constitucional da solidariedade. Dois fatos são cediços: a construção de uma sociedade livre, justa e solidária se afigura como um dos objetivos da República; e o valor do trabalho social é um dos fundamentos do Brasil. Diante disso, não há como negar que o trabalho é um dos instrumentos a ser utilizado para alcançar o objetivo exposto, evidenciando, assim, sua estreita relação. 
Além disso, os ensinamentos acerca da consciência coletiva - aquela que está presente na solidariedade mecânica - também permitem construir uma forte relação entre o trabalho social e a solidariedade. Segundo assevera Cardoso (2013, p. 136), “[...] a solidez, o tamanho ou a intensidade dessa consciência coletiva é que irá medir a ligação entre os indivíduos, variando segundo o modelo de organização social de cada sociedade”. Destarte, é amplamente possível afirmar o seguinte: uma organização social que valoriza o trabalho e se preocupa com seu valor perante a sociedade, por consequência é, também, uma sociedade que valoriza a solidariedade social, sendo que esta contribui, por sua vez, para o atingimento da solidariedade jurídica presente na Carta Magna de $1988^{216}$.

Encaminhando o trabalho para o final, os apontamentos trazidos neste artigo, ainda que bastante breves, permitiram demonstrar que a divisão do trabalho social gera, sim, uma espécie de solidariedade social. Contudo, essa solidariedade não é apenas social, mas jurídica, especialmente porque a Constituição da República Federativa do Brasil de 1988, mediante sua força normativa, impõe a todos o dever de construção de uma sociedade livre, justa e solidária. Neste passo, proteger o valor social do trabalho, salvo melhor juízo, não é “apenas” proteger o direito ao desenvolvimento, à erradicação da pobreza, à dignidade humana, etc. Significa amparar, de igual forma, o projeto constitucional de cunho solidarista.

\section{CONSIDERAÇÕES FINAIS}

Não obstante os argumentos construídos ao longo desta pesquisa sejam breves e com algumas arestas não aparadas, algumas conclusões saltam aos olhos. A primeira delas diz respeito ao próprio trabalho, na sua mais pura essência. Em uma época distante, a atividade laboral era considerada algo indigno, capaz de causar até mesmo vergonha aos homens. No entanto, essa realidade não mais pertence aos dias atuais. Hoje, não há como negar a essencialidade do trabalho, seja para garantir a subsistência, seja para dignificar o homem.

Tal situação justifica a ampla proteção concedida ao trabalho por parte da Constituição da República Federativa do Brasil de 1988, a qual estabelece a importância do trabalho para os cidadãos e, também, para o desenvolvimento da sociedade. Se o trabalho traz dignidade para o

\footnotetext{
${ }^{216}$ Evidenciando ainda mais a relação entre os estudos desenvolvidos por Émile Durkheim e a solidariedade, é de bom alvitre mencionar que foi o solidarismo sociológico, criado a partir de seus pensamentos, que serviu de base para o desenvolvimento da teoria que compreende a solidariedade com um viés jurídico.
} 
homem, indubitavelmente o mesmo compõe o catálogo de direitos fundamentais sociais do Brasil.

Diante de tais aportes, é possível chegar a uma segunda conclusão: se o trabalho está amplamente protegido pela Carta Magna de 1988 e o princípio constitucional da solidariedade, conforme disposição do mesmo diploma, trata-se de um objetivo a ser atingido pela nação, como negar que existe uma relação entre tais elementos? Se fazem parte do mesmo texto constitucional, por óbvio, necessitam estar em harmonia.

Desta feita, é possível afirmar, também, que a divisão do trabalho social é capaz de gerar uma espécie de solidariedade, a qual pode ser melhor elucidada mediante a comparação com o organismo humano: cada órgão possui sua finalidade e sua individualidade. Porém, para que o corpo funcione é preciso que todos os órgãos trabalhem conjuntamente. Assim deve ser com relação à sociedade: se cada indivíduo possui aptidões e, igualmente, necessidades, porque não suprir tais lacunas mediante as habilidades de outros indivíduos? Esse possível intercâmbio de aptidões é capaz de gerar atos solidários, transformando "partes" em um “todo" e, ainda, fomentar o desenvolvimento social.

Se a divisão do trabalho social proposta por Émile Durkheim dá azo à cooperação e a solidariedade entre os homens, é totalmente possível afirmar que ela possui uma íntima relação com o princípio constitucional da solidariedade, o qual preza a colaboração, a preocupação com relação ao próximo, o compartilhamento e, sobremaneira, a superação do individualismo. Ademais, a solidariedade gerada por meio da divisão do trabalho social se coaduna com um dos principais objetivos do Brasil, qual seja: a construção de uma sociedade livre, justa e solidária. Nesse ínterim, para além dos dispositivos protetores do trabalho, o princípio constitucional da solidariedade também ampara o valor social contido nesta atividade e, assim sendo, funciona como um instrumento de autopromoção e, igualmente, que enaltece o trabalho e que enfatiza a sua importância para a sociedade.

\section{REFERÊNCIAS}

AGOStinHO, Santo. A cidade de Deus. Lisboa: Fundação Calouste Gulbenkian, 2000.

ARAÚJO, Francisco Rossal de; COIMBRA, Rodrigo. Apontamentos sobre a hierarquia das normas no direito do trabalho. In: TORRES, Artur. (Org.). Direito e processo do trabalho: escritos em homenagem aos 20 anos de docência do professor Gilberto Stürmer. Porto Alegre: Arana, 2013. 
ARISTÓTELES. Ética a nicômaco. Tradução de Torrieri Guimarães. São Paulo: Martin Claret, 2012.

Política. Tradução de Pedro Constantin Tolens. São Paulo: Martin Claret, 2008.

BODENHEIMER, Edgar. Teoría del derecho. México: FCE, 1994.

BRASIL. Constituição (1988). Constituição da República Federativa do Brasil. Brasília, DF: Senado Federal, 1988. Disponível em: <http://www.planalto.gov.br/ccivil_03/ constituicao/constituicao.htm>. Acesso em: 20 ago. 2016.

CAETANO, Érika de Cássia Oliveira. A divisão do trabalho: uma análise comparativa das teorias de Karl Marx e Emile Dürkheim. Disponível em:<http://www2.pucminas.

br/imagedb/documento/DOC_DSC_NOME_ARQUI20060410095823.pdf >. Acesso em: 20 ago. 2016.

CARDOSO, Alenilton da Silva. Princípio da solidariedade: o paradigma ético do direito contemporâneo. São Paulo: Ixtlan, 2013.

COMPARATO, Fábio Konder. A civilização capitalista: para compreender o mundo em que vivemos. São Paulo: Saraiva, 2013.

DALLARI, Dalmo de Abreu. Elementos da teoria geral do estado. 21 ed. São Paulo: Saraiva, 2000.

DELGADO, Mauricio Godinho. Curso de direito do trabalho. 11 ed. São Paulo: LTr, 2012.

DUGUIT, Léon. Fundamentos do direito. Tradução de Márcio Pugliesi. São Paulo: Ícone, 2006.

DURKHEIM, Émile. Da divisão do trabalho social. Tradução de Eduardo Brandão. São Paulo: Martins Fontes, 1999.

GÓES, Maurício de Carvalho; ENGELMANN, Wilson. Direito das nanotecnologias e o meio ambiente do trabalho. Porto Alegre: Livraria do Advogado, 2015. 
LEVINE, Donald Nathan. Visões da tradição sociológica. Tradução de Álvaro Cabral. Rio de Janeiro: Zahar, 1997.

LÔBO, Paulo Luiz Netto. O Princípio constitucional da solidariedade nas relações de família. In: CONRADO, M., PINHEIRO, R. F. (Coords.). Direito privado e constituição: ensaios para uma recomposição valorativa da pessoa e do patrimônio. Curitiba, Juruá, 2009.

MACHADO, Raimar Rodrigues; CARVALHO, Sonia Aparecida de. O direito fundamental do trabalhador ao meio ambiente do trabalho salubre como princípio de proteção. In: GORCZEVSKI, Clovis; LEAL, Mônia Clarissa Hennig. (Org.). Constitucionalismo contemporâneo: garantindo a cidadania, concretizando a democracia. Curitiba: Multideia, 2014.

MACHADO, Raimar Rodrigues. O trabalho humano frente à ideia de liberdade. In: COSTA, Marli Marlene Moraes da; LEAL, Mônia Clarissa Hennig. (Org.). Direitos sociais e políticas públicas: desafios contemporâneos. Santa Cruz do Sul: EDUNISC, 2012.

MORAES, Maria Celina Bodin de. O Princípio da solidariedade. In: MATOS, A. C. H. (Org.). A construção de novos direitos. Porto Alegre: Núria Fabris, 2008. Disponível em: <http://www.tepedino.adv.br/wp/wp-content/uploads/2012/09/biblioteca9.pdf>. Acesso em: 20 ago. 2016.

MUSSE, Ricardo. Émile Durkheim: fato social e divisão do trabalho. São Paulo: Ática, 2007.

OLIVEIRA, Luís Fernando Lopes de. Direito de família e princípio da solidariedade: o princípio constitucional da solidariedade como direito fundamental e a sua incidência nas relações familiares. Curitiba: Juruá, 2014.

ORGANIZAÇÃO DAS NAÇÕES UNIDAS (ONU). Declaração Universal dos Direitos do Homem. 1948. Disponível em: <www.dudh.org.br/wp-content/uploads/2014/12/dudh.pdf〉. Acesso em: 20 ago. 2016.

REIS, Jorge Renato dos; KONRAD, Letícia Regina. O direito fundamental à solidariedade: a aplicação do instituto no direito civil. Revista Novos Estudos Jurídicos, n. 1, p. 59-87, jan./abr. 2015.

REIS, Suzéte da Silva; NUNES, Josiane Borghetti Antonelo. A dignidade do trabalho e a emancipação social. In: COSTA, Marli Marlene Moraes da; TERRA, Rosane Beatris Mariano da Rocha Barcellos; REIS, Suzéte da Silva. (Org.). Direitos Sociais, trabalho e educação. Curitiba: Multideia, 2011. 
SARLET, Ingo Wolfgang. A eficácia dos direitos fundamentais: uma teoria geral dos direitos fundamentais na perspectiva constitucional. 11 ed. Porto Alegre: Livraria do Advogado, 2012.

SARMENTO, Daniel; GOMES, Fábio Rodrigues. A eficácia dos direitos fundamentais nas relações entre particulares: o caso das relações de trabalho. Disponível em: Rev. TST. Brasília, vol. $77^{\circ}, \mathrm{n}^{\mathrm{o}}$ 4, out/dez 2011. Disponível em: < <http://aplicacao.tst.jus.br/dspace/handle/1939/28342>. Acesso em: 20 ago. 2016.

SOARES, Flaviana Rampazzo. Responsabilidade civil por dano existencial. Porto Alegre: Livraria do Advogado, 2009.

WESTPHAL, Vera Herweg. Diferentes matizes da ideia de solidariedade. Revista Katálysis, Florianópolis, v. 11, n. 1, jan./jun. 2008. Disponível em:

<https://periodicos.ufsc.br/index.php/katalysis/article/view/4757>. Acesso em: 20 ago. 2016.

\title{
THE RELATIONSHIP BETWEEN THE SOCIAL WORK PROPOSED BY ÉMILE DURKHEIM AND THE CONSTITUTIONAL PRINCIPLE OS SOLIDARITY FORESEEN IN THE FEDERAL CONSTITUTION OF 1988
}

\begin{abstract}
This work aims to verify if there is, indeed, a relationship between social work proposed by Émile Durkheim and the constitutional principle of solidarity, since both are subject to supervision by the Brazilian Federal Constitution of 1988. Thus, in the first reading the article will brief notes about the social work and also about the Labour Law. Following, the historical premises of the constitutional principle of solidarity will be analyzed, as well as its contemporary treatment. Finally, the work will determine, based on the main characteristics of each institute - social work and the constitutional principle of solidarity - if it is possible to establish, in fact, any relationship between them. Without pretending to exhaust the subject at hand, it is believed that the general lines characterizing the mechanisms studied here are able to give rise to a very close relationship between them, as if both are protected by the Brazilian Federal Constitution of 1988, it is necessary harmonize. In this step, since the article has bibliographic nature, will be used the approach methods of deductive and historical-critical and the research technique will make use of indirect documentation.
\end{abstract}


Keywords: Social work. Constitutional principle of solidarity. Émile Durkheim. Division of labor. 